\title{
Epistemic practices in Bio Art
}

\author{
Suzanne Anker ${ }^{1}$
}

Received: 11 April 2019 / Accepted: 4 January 2021 / Published online: 8 February 2021

(c) The Author(s), under exclusive licence to Springer-Verlag London Ltd., part of Springer Nature 2021, corrected publication 2021

\begin{abstract}
This paper addresses three aspects of Bio Art: iconography, artificial life, and wetware. The development of models for innovation require hybrid practices which generate knowledge through epistemic experimental practices. The intersection of art and the biological sciences contain both scientific data as well as the visualization of its cultural imagination. In the Bio Art Lab at the School of Visual Arts, artists use the tools of science to make art.
\end{abstract}

Keywords Bio Art $\cdot$ Epistemic things $\cdot$ Altering nature $\cdot$ Art and science $\cdot$ Picturing DNA $\cdot$ Climate change $\cdot$ Hybrid practices

Streams of unique projects, processes and collaborations currently underlie exploratory and investigatory models for innovation in both science and art. While science aims at repeatability, and its knowledge acquisition generally is expressed numerically, art is more diaphanous. The role of consensus in art is expressed within its own distinct terms, relying on art history and cultural and museum studies. The current upswing of enterprises, conferences, exhibitions and artist-in-residence programs in scientific laboratories embodies this developing conjunction between visual art and the biological sciences. Increasingly, art academies are initiating such courses in their own studios, while inviting scientists to collaborate on an expanding range of projects.

The School of Visual Arts' Bio Art Laboratory was founded in 2011 by this author as part of the BFA Fine Arts Department's new facility consisting of 54,000 square feet in the heart of the Chelsea District in New York City. It is conceived of as a place where scientific tools and techniques become tools and techniques for art practice. Projects include: tissue engineering of plants, painting with fluorescent bacteria, using Scoby and Mycelium cultures as sculptural materials, as well as forays into molecular cuisine

Suzanne Anker

suzanne.anker@gmail.com

1 School of Visual Arts, BFA Fine Arts Department, $335 \mathrm{~W}$ 16th Street, New York, NY 10011, USA techniques. Some of the technical devices in the Bio Art Lab are: a bioprinter, microscopes, incubators, vortex mixers, autoclave sterilizers and a chemical fume hood among others. The Bio Lab also houses skeletons, specimen and slide collections, an herbarium, an aquarium, as well as a library. It is a hybrid chamber filled with plants, fish and coral, appearing like a fecund mix between nineteenth century and twenty-first century laboratory practices. (Figs. 1, 2).

From anatomical studies to landscape painting to the biomorphism of surrealism, the biological realm historically provided a robust resource for many significant artists. Recently, Bio Art emerged as a term referring to intersecting domains of the biological sciences and their incorporation into the plastic arts. Bio Art is a contested term, whose origins are not clearly accounted for, although there have been claims otherwise. ${ }^{1}$ Of particular importance in Bio Art is its capacity to summon awareness of the ways in which advancing biotechnologies alter social, ethical and cultural values in society.

In 2004, the late sociologist of science Dorothy Nelkin and I sought to create a platform for this subject in The Molecular Gaze, Art in the Genetic Age, ${ }^{2}$ published by Cold Spring Harbor Laboratory Press. The text interwove art history,

\footnotetext{
${ }_{1}$ Suzanne Anker, David Yager,and JD Talesek.Visual Culture and Bioscience: Issues in Cultural Theory, No 12.

(Center for Art, Design and Visual Culture, UMBC, Cultural programs of the National Academy of Sciences,

Washington, D.C, 2009.

${ }^{2}$ Suzanne Anker and Dorothy Nelkin, The Molecular Gaze, Cold Springs Harbor Laboratory Press, 2004.
} 


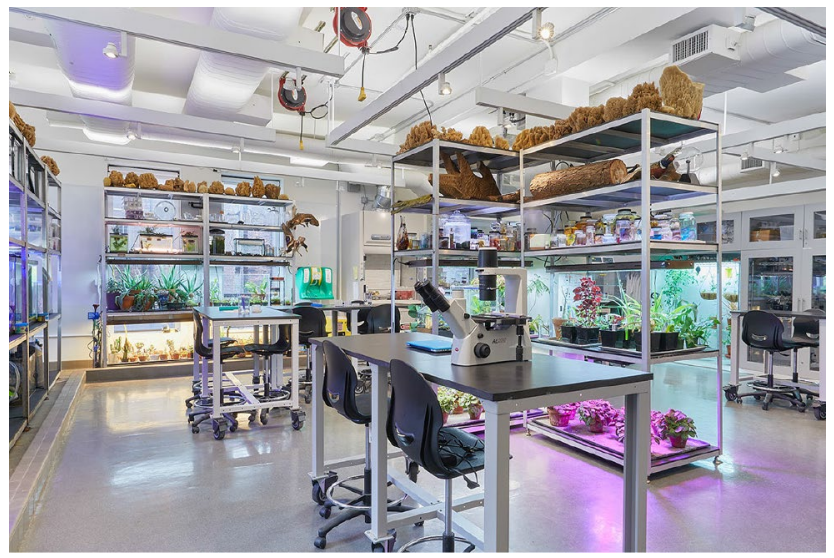

Fig. 1 School of Visual Arts Bio Art Laboratory. Photo credit: Jung Hee Mun

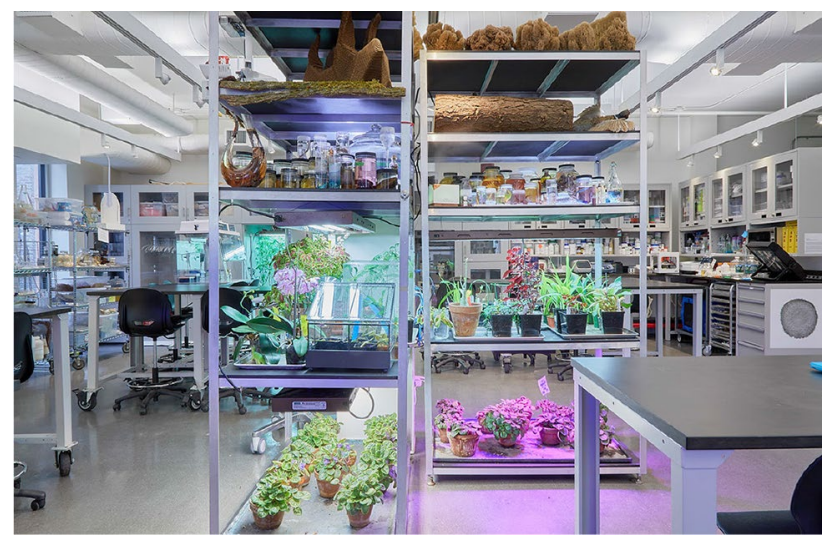

Fig. 2 School of Visual Arts Bio Art Laboratory. Photo credit: Jung Hee Mun

contemporary art, and social policy, thereby creating a flexible spectrum among these disciplines. Reviewed by scientist Evelyn Fox Keller, ${ }^{3}$ who commented that "art can function as a form of cultural critique, expressing cultural anxieties, disrupting conventional platitudes, transgressing accepted boundaries." Such are some of the additional attributes which Bio Art posits with questions concerning the radical alterations of nature, both intended and unintended.

Arriving in the late 1980s and the early 1990s, Bio Art is neither media specific nor locally bounded. It is an international movement with practitioners in such regions as Europe, the U.S., Russia, Asia, Australia and the Americas. Several sub-genres of Bio Art exist within this overarching term ${ }^{4}$ :

\footnotetext{
${ }^{3}$ Evelyn Fox Keller, Art in the Genetic Age Bio Essays 26:817 2004, Wiley Periodicals, Inc. p.817.

4 Suzanne Anker, Bio Art, Grove Art Online https://doi.org/10.1093/ gao/9781884446054.article.T2088795 19 September 2010.
}

1. Artists who employ the iconography of the twentieth and twenty-first century sciences, including molecular and cellular genetics, transgenically altered living matter, reproductive technologies and the neurosciences. All traditional media, including painting, sculpture, printmaking, drawing, and performance art, are employed to convey novel ways of reflecting on life forms and their attendant implications.

2. Artists who utilize computer software, systems theory, and simulations which investigate aspects of the biological sciences such as evolution, artificial life, and robotics through digital sculpture and new media installations, films, and video.

3. Artists employing biological material itself, and wetware practices as their medium, including processes such as tissue engineering, plant breeding, transgenics and ecological reclamation.

The burgeoning fields of Bio Art, Bio Design and Bio Architecture $^{5}$ continue to develop models for innovation, communication and expression. There is, in addition, an evolving preserve addressing the development of ideas inherent in such hybrid-practices. While Leonardo da Vinci is often cited as the individual encompassing mastery in art and science, the incorporation of digital media in both disciplines form an authentic bridge summoning modifications in traditional stereotypical definitions. Innovations often occur with an awareness of factors arising from accident or random circumstances in both these disciplines. Discrete tools are invented in each field to engage the necessities of unique research methods. Such aspects of mutual cognitive recognition also link art and science.

Epistemic things, as referred to by Hans-Jorg Rheinberger $^{6}$ are those objects of investigation which generate knowledge in experimental systems. One example is Kary Mullis ${ }^{7}$ apparatus for replicating DNA through the process of electrophoresis and PCR technologies. By multiplying DNA fragments into persuasive quantities, genetic research was revolutionized by his critical apparatus. From forensic evidence to paternal substantiation to scientific research and discovery, this device is the gold standard for DNA replication. Innovations in science are dependent on designing tools for original procedures which generate foundational knowledge and become a sector within Bio Art's trajectory. The

\footnotetext{
5 Mitchell Joachim, Maria Aiolova, Design with Life: Biotech Architecture and Resilient Cities, Actar Publishers, December 2019.

${ }^{6}$ Hans-Jorg Rheinberger, Toward a History of Epistemic Things. Stanford Univ. Press, 1997.

7 Kary Mullis, The unusual origin of the polymerase chain reaction. Scientific American, April 56-65, 1990.
} 
Fig. 3 Crystallography image of insulin by Dr. Helen Megaw

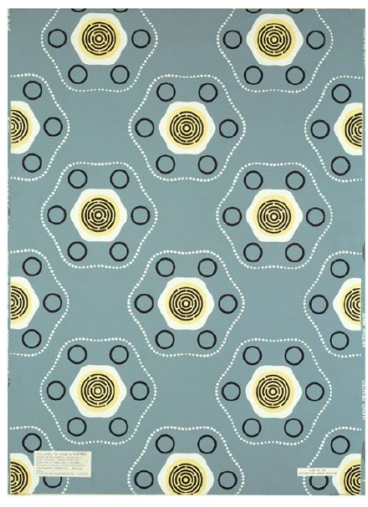

tools themselves are part of the resulting data, thereby creating new organisms, models, and information. These aspects are inseparable from wet ware and therefore converge into one another in Bio Art practices.

Images, as well, are instrumentally employed in biology. They also achieve, in their metaphorical outreach, an ability to capture the culture's collective imagination. They are connected to material and process and become part of the data set involved in codified information, including its subsequent dissemination. Like wet ware and it is instruments, they are part of the three-fold operation of epistemic processes which in turn usher in scientific discoveries (and philosophical debate) influencing social, political and economic policies.

Take for another example, Rosalind Franklin's infamous Photo $51,{ }^{8}$ the key image employed to picture the double helix of DNA which lead to the discovery of its molecular structure. The process, which was lengthy, arduous, and even dangerous in the 1950s, consisted of prolonged exposures of $\mathrm{X}$-rays passing through a crystal, thus unmasking discrete diffraction patterns explicating molecular arrangements. Franklin's photos of both the A form and B form of DNA led to the Watson, Crick and Williams Nobel Prize. ${ }^{9}$ While Watson and Crick explored the possible configurations of this molecule in a 3-D constructed model, without Franklin's image such work would never have been realized at that time.

Images also have cultural manifestations, as new methodologies come into play. Yet another example is the work of Dr. Helen Megaw, ${ }^{10}$ crystallographer at the Cavendish Laboratory at Cambridge. Acknowledging the delicate designs exposed by this technique, she was a central figure in the Festival Pattern Group, which consisted of textile

\footnotetext{
8 "Secret of Photo 51. Nova". PBS.

9 Watson, James D. (1980). The Double Helix: A Personal Account of the Discovery of the Structure of DNA (1968). Atheneum. ISBN 978-0-689-70,602-8.

${ }^{10}$ Dr. Helen Megaw's pioneering work in determining the structure of ice crystals led to the naming of an island in Antarctica called Megaw Island.
}

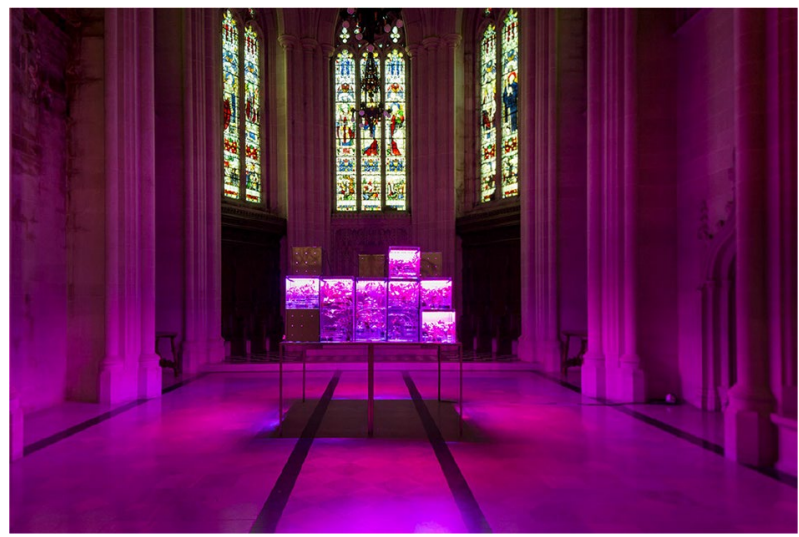

Fig. 4 Astroculture (Eternal Return) (2015), Cathedral of St. John the Divine, NYC. Photo credit: Raul Valverde

manufactures and crystallographers. They created prints revealing the properties of insulin, hemoglobin and china clay. ${ }^{11}$ (Fig. 3).

To follow: a number of projects that have been exhibited nationally and internationally as examples of Bio Art from the provenance of SVA's laboratory. For instance, Astroculture (2015) is a sculptural installation that has been exhibited at the Cathedral of St. John the Divine in NYC (Fig. 4), the Daejeon Biennial, in Korea, (which was exclusively devoted to Bio Art), the Silos of Sawyer Yards in Houston, Texas, the Everson Museum in Syracuse, NY, Art Laboratory Berlin, and most recently, the Burlington City Arts in Vermont. ${ }^{12}$ Taking a tour between art museums, art galleries, churches and defunct rice silos, Astroculture sprouted and grew a variety of vegetables and herbs, from peas and beans to lettuce and tomatoes. (What is essential to note, is that seeds and soil cannot travel internationally without government documentation, so like humans they must carry "passports").

As an indoor vegetable and herb garden, Astroculture is similar to both a terrarium and a Wunderkammer, ${ }^{13}$ while also relating to NASA's ongoing space program. With the rise of biotechnologies and the tinkering with living systems, what vast resources are available in outer (and deep) space

\footnotetext{
11 Ann Coxon, "From Atoms to Patterns", Frieze Magazine, Issue 117, September 2008. Archived from the original (http:www.wellc omecollection.org/whats-on/exhibitions/from-atoms-to-patterns.aspx. Lomas, Elizabeth (2001). Guide to the Archive of Art and Design, Victoria \& Albert Museum. Taylor \& Francis.

${ }^{12}$ The Value of Food, curated by Kirby Gookin and Robin Kahn, (2016),Daejeon Biennale 2018-BIO, curated by Bobae Lee, (2018), Outa Space at Site Gallery, Sawyer Yards, Sculpture Month Houston, 2019, curated by Volker Eisele, 1.5 Degrees Celsius, Everson Museum, curated by DJ Hellerman, etc.

13 A Wunderkammer is also known as a cabinet of curiosities becoming popular in the sixteenth century in Europe. It was a collection of items from both the natural world and man-made objects.
} 
Fig. 5 Astroculture, detail showing green plants under red and blue lights. Photo credit: Raul Valverde
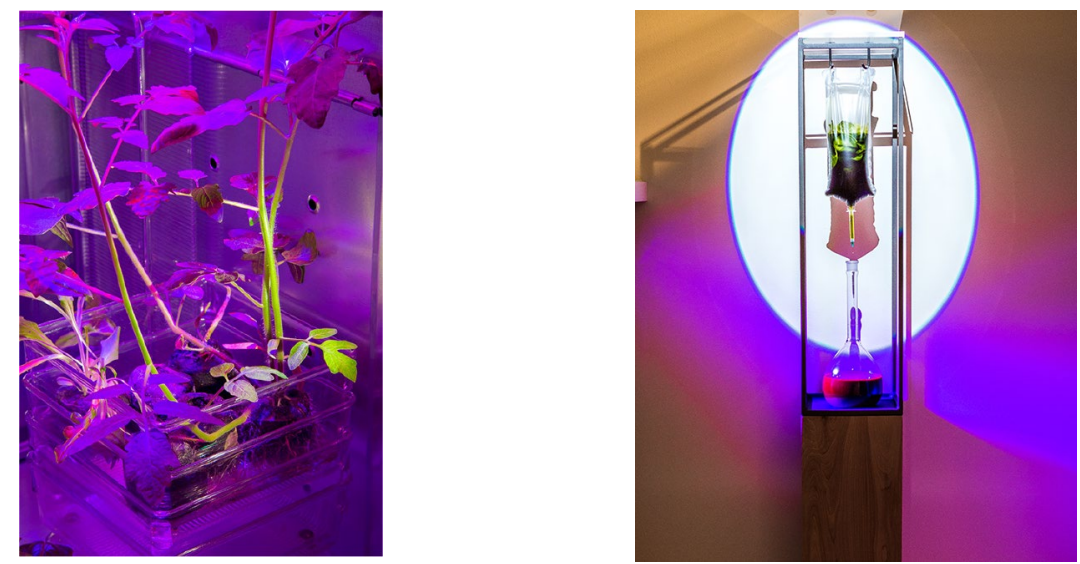

Fig. 7 Tarah Rhoda, Ourglass (2017)

insure a secure supply of food and medicine from botanical sources.

Andrew Cziraki's, Bornless One (2016) (Fig. 6) is a work which samples Holy Water from various Catholic Churches in Manhattan and Brooklyn, New York. Such "Holy Water" is employed in sacramental rites conducted by the Church to cleanse sins and protect against evil doings. While it had been known that since the nineteenth century, Holy Water contained many forms of bacteria, leading to various infections; nevertheless, it still remains a staple practice in a preserve of religious ceremonies. Cziraki gathered 45 samples of Holy Water and worked with a scientist using molecular biology techniques to gather DNA remnants contained in the liquid. The prepared samples were then sent to an outside lab to complete the metagenomic process. The results were astonishing: sequences were found from tomatoes, corn, rice, big horned sheep, an Egyptian fruit bat, rats, round worms, fish, kiwi, African crocodilian tapeworm and bacteria associated with irritable bowel syndrome, among others.

The findings were installed as an installation of framed scientific journal pages containing the megagenomic data along with glass cylinders containing rice and fruit referring to the found sequences. In his thesis statement, Cziraki refers to this piece thus: "the communities we live in on a macro level can also reflect aspects of our existence on the micro level." In extensive gatherings, participants gather from diverse communities and in particular, during this time of globalization, traverse the borderless world at large.

Microbes have been at the forefront of medicine over the past several decades. From the study of microbiomes living in a human gut, to plentiful examples of zoonosis, ${ }^{14}$ the

\footnotetext{
${ }^{14}$ Zoonosis is the transmission of a disease from an animal to a human. These infections can be caused by a parasite, virus, bacteria and fungus. Examples include Lyme's disease. Ebola and Covid-19.
} 


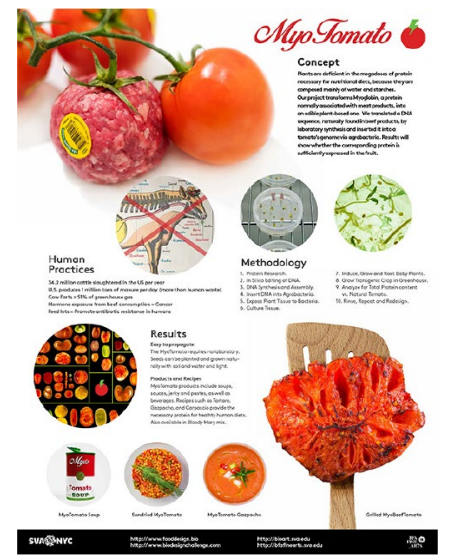

Fig. 8 Myotomato Poster (2016). Design credit: Raul Valverde

jumping of viruses from animals to humans, to the reemergence of measles due to the resistance of various communities to vaccinate. Viruses can infect through water, mud, air or blood. ${ }^{15}$ Is this analysis, altering the ways in which science and religion interact a consideration for the furtherance of the public good?

Another work which has evolved through the facility of the Bio Art Lab is Tarah Rhoda's Ourglass (2017), (Fig. 7) which compares photosynthesis to respiration. Plants employ chlorophyll, a green pigmented substance contained within the plant's chloroplast. This is a parallel structure in plants relating to cells in humans. By employing light and energy, green plants are able to synthesize water and carbon dioxide to generate sugar. Such a self-sustaining apparatus, not only converts carbon dioxide into oxygen as a by-product, but allows plants to grow and prosper while actually reducing the carbon footprint.

In humans, however, metabolic exchanges occur through hemoglobin, a red pigmented oxygenating protein found in blood. Here the protein circulates oxygen throughout the lungs, which in turn oxygenate the body's cells and tissues. The by-product of this exchange is the excretion of carbon dioxide.

In Ourglass, a viewer is alerted to the fact that chlorophyll's light absorption property remains active even when the substance is removed from a plant. By boiling the leaf and allowing it to then simmer in alcohol, the chlorophyll will convert the clear alcohol to green. However, when exposed to UV light, the solution will glow red in the chromatic intensity of blood. Once again, we are reminded of the wondrous nature of chemical equations, and how their living processes, although discretely separate, maintain a

\footnotetext{
15 Carl Zimmer, "Welcome to the Virosphere", The New York Times, March 24, 2020.
}

wide diversity of functions. They form a web-one that has no weaver ${ }^{16}$ but whose constituent parts dynamically comingle and interrelate.

And finally, a project entitled Myotomato (2016) (Fig. 8) submitted for consideration at the Bio Design Challenge ${ }^{17}$ presented at MoMA in New York City. It consisted of wet lab practices, constructed models, video, photography as well as food recipes. The idea governing this project derived from the variety of tomato commonly known as the "beefsteak tomato", a play on words. ${ }^{18}$ Such tomatoes are known for their mammoth size and delicious taste; although in their original state in the southern hemisphere, this fruit was the size of berries. It has been recently determined in scientific analysis that such a tomato arose due to genetic mutations, making it a living testube for manipulation. ${ }^{19}$ Most tomatoes lack megadoses of proteins necessary for a human's diet, although vitamins and minerals abound. Therefore, our project engaged genetic engineering of the tomato's genome with myoglobin, a similar protein related to the hemoglobin in red blood cells. This genetic alteration was intended to increase the quantity of protein residing in this fruit. ${ }^{20}$

With laboratory synthesis, we inserted myoglobin into the tomato plant's genome via agrobacteria. We complied with a variety of necessary steps, including protein research, in silico editing of DNA, and the tissue culturing of plants, which were then grown into full size and did produce tomatoes. It was confirmed through electrophoresis that this transfer did actually take place, and that the protein rich myoglobin resided in such plants. However, we could not ascertain which exact sectors of the plants carried the said protein; and how much protein was in fact, being produced. To carry this project further would require scientific expertise in the field of botany which were unavailable to us at the time. As a Bio Art project, our speculative idea proved useful with regard to discussing the need for creating protein-based food with low carbon footprints, thus feeding a swelling population.

Our intent driving the project was to significantly reduce the cattle populations slaughtered for food production, and the amount of methane thereby absorbed into

\footnotetext{
${ }^{16}$ Ted j. Kaptchuk, The Web That Has No Weaver (McGraw Hill Education) 2000, p.14-15.

17 The Biodesign challenge is an educational competition bringing together participants from universities around the world. Each team, or school, works in conjunction with scientists to create projects employing a biological aspect that could aid in energy consumption, climate change, food production among others.

18 The Beefsteak tomato exists in several varieties: Big Beef, Brandywine, and Cherokee Purple to name a few. They are rich in vitamin $\mathrm{A}$ and $\mathrm{C}$.

19 https://www.newfoodmagazine.com/news/17732/scientists-revealthe-origin-of-beefsteak-tomatoes/

20 Although the tomato is a fruit, it was designated in 1883 , by the Supreme Court that it was a vegetable due to taxation purposes.
} 
the atmosphere. Thus, tomato seeds carrying significant amounts of protein could be grown worldwide at low cost, and consequently, aid malnourished populations whose food supplies are subject to frequent and repeated lethal interruption.

More recently, plant-based "burgers" are hitting the market, such as the Impossible Burger and the Beyond Burger. The Impossible Burger employs heme, an iron-containing compound which gives the plant-based burger its savory allure. This is indirect and persuasive evidence that speculative Bio Art projects, like Myotomato, are relevant with regard to expressing while exposing aspects of global concerns relating to personal and planetary health.

In conclusion, the above examples (there are many more) point to the methods by which science has sprung out of the laboratory and into our lives. At the other end of the equation, visual art's critical reach, which directs its ability in pursuing random methods of inquiry, is equal and essential. Innovative comprehension, and the subsequent creation of novel tools is also necessary when addressing the twentyfirst century's ceaseless and fluctuating dynamics which remain manifestly complex.

More importantly, how is the idea and nomenclature of Bio Art to be framed? If live materials are considered a necessary part of this subject, then, in a stretch, a viewer sitting in a gallery with a common cold could be considered an example of Bio Art.
In experiments addressing the scientific results of Bio Art, where are the peer-review panels? Are we supposed to take someone's word that an actual experiment did, in fact, produce the results reported? Are Bio Artists nothing but amateur scientists? What is the essential criteria for judging the significance of Bio Art? Can Bio Art be separated from Bio Design? What role does sheer speculation play in creating Bio Art?

Finally, Bio Art can be understood as a three pronged practice involving wetware, tool production, and visualization. The most relevant aspect of this expanding genre is the fostering of discussions concerning alterations of nature, as the German philosopher Jurgen Habermas explains inThe Future of Human Nature. ${ }^{21}$ For social scientist Katherine Waldby, ${ }^{22}$ we are all one genetic sequence away from the monstrous. And for the eighteenth century poet and philosopher Novalis, it is the unknown that brings wonder to bear. As we undergo paradigmatic shifts in current society, as in its techno-scientific revolutions and collapsing eco-systems, repositioning our acquisition of knowledge-producing systems is key to a speculative redesigning of the future.

Publisher's Note Springer Nature remains neutral with regard to jurisdictional claims in published maps and institutional affiliations.
21 Jurgen Habermas, The Future of Human Nature, Polity, 2003.

22 Catherine Waldby, Tissue Economies: Blood,Organs and Cell Lines in Late Capitalism, Duke University Press, 2006. 